\title{
Absence of nectar resource partitioning in a community of parasitoid wasps
}

\author{
Myles H. M. Menz ${ }^{1}$ Graham R. Brown ${ }^{2,3}$ • \\ Kingsley W. Dixon ${ }^{4,5} \cdot$ Ryan D. Phillips ${ }^{5,6}$
}

Received: 18 May 2015/ Accepted: 19 July 2015/Published online: 28 July 2015

(C) Springer International Publishing Switzerland 2015

\begin{abstract}
Parasitoid wasps occur in diverse communities, with the adults of most species sourcing carbohydrates from nectar or honeydew. However, the role of niche partitioning of nectar resources in maintaining diverse communities of parasitoid Hymenoptera is poorly known. To elucidate patterns of nectar resource use and test whether species partition resources, we investigated pollen loads in a community of parasitoid thynnine wasps in the biodiversity hotspot of southwestern Australia. In total, 304 thynnine wasps from 28 species were captured. Eighteen of these species are undescribed, highlighting the high diversity of unrecognized species in southwestern Australia. Pollen loads were detected on 111 individuals representing 19 species. Six pollen types were identified. All species that carried pollen primarily visited two tree
\end{abstract}

Electronic supplementary material The online version of this article (doi:10.1007/s10841-015-9793-2) contains supplementary material, which is available to authorized users.

Myles H. M. Menz

myles.menz@iee.unibe.ch

1 Institute of Ecology and Evolution, University of Bern, Baltzerstrasse 6, 3012 Bern, Switzerland

2 Museum and Art Gallery of Northern Territory, GPO Box 4646, Darwin, NT 0801, Australia

3 Research Institute for Environment and Livelihoods, Charles Darwin University, Darwin, NT 0909, Australia

4 Department of Agriculture and Environment, Curtin University, Bentley, WA 6102, Australia

5 Kings Park and Botanic Garden, Fraser Avenue, West Perth, WA 6005, Australia

6 Evolution, Ecology and Genetics, Research School of Biology, The Australian National University, Canberra, ACT 0200, Australia species, Agonis flexuosa and Eucalyptus marginata, in the Myrtaceae. The other four pollen types were only recorded from single wasps. There was no evidence of nectar-resource partitioning. This may be due to these Myrtaceae producing abundant, open-faced flowers. Wasp species that were not recorded carrying pollen may utilise other carbohydrate sources, such as homopoteran honeydew. Niche partitioning is predicted to occur during the parasitoid larval phase of the life cycle. This study highlights the importance of nectariferous Myrtaceae in supporting diverse wasp communities. Further, two species of nectarforaging wasps collected here are involved in the pollination of rare orchid species. Hence, conservation and management of habitats that support floriferous Myrtaceae are important for both the maintenance of diverse wasp communities, and the plants they pollinate.

Keywords Foraging ecology · Hymenoptera ·

Myrtaceae · Orchid · Pollination · Pollen load · Thynnidae

\section{Introduction}

Understanding the mechanisms that allow for the maintenance of diverse biological communities is both a fundamental objective of ecology and critical for the management of conservation reserves. Theoretically, niche partitioning reduces competition between species, thus allowing a diversity of species to coexist (MacArthur 1958; MacArthur and MacArthur 1961; Levine and HilleRisLambers 2009). For example, co-occurring species may partition resources trophically, spatially, or temporally (Pianka 1973). Parasitoid wasps are considered to be one of the most speciesrich animal groups (LaSalle and Gauld 1991), and can exhibit extremely high local species richness and cryptic 
diversity (e.g. Smith et al. 2008; Veijalainen et al. 2012, 2014). Most parasitoids require carbohydrates as adults, as an energy source to support activity and/or oogenesis (Jervis et al. 1993, 2008). In many families of parasitoid, carbohydrates are usually taken in the form of nectar or honeydew produced by plant-feeding Hemiptera (e.g. Jervis et al. 1993, 2008). However, systematic studies investigating foraging preference and food resource partitioning in communities of adult parasitoids are scarce (Jervis et al. 1993; Wäckers 2004).

Thynnine wasps are a diverse family of parasitoid wasps with a primarily Australian distribution (Austin et al. 2004). They are best known for their role in the pollination of numerous genera of sexually deceptive orchids, where they are attracted to the flower by mimicry of sex pheromones (Stoutamire 1974, 1983; Bower 1996; Schiestl et al. 2003; Hopper and Brown 2007; Phillips et al. 2009; Bohman et al. 2014). However, some species appear to regularly forage for nectar (Brown and Phillips 2014), where they may also be important pollinators. While over 600 species have been described, ongoing taxonomic and pollination studies have revealed an immense diversity of undescribed taxa at both the species and generic level (Brown 2009; Peakall et al. 2010; Griffiths et al. 2011; Menz et al. 2015). Further, observations of aggregations of mating pairs on nectar plants have shown a high diversity of co-occurring species (Alcock 1981; Phillips et al. 2009).

Thynnine wasps have a unique life cycle where the wingless females call to attract the winged males using pheromones (Alcock 1981; Schiestl et al. 2003; Bohman et al. 2014). They then mate during flight, where the male transports her to a food source, either feeding her directly or allowing her to forage, before dropping her back on the ground (Ridsdill-Smith 1970a; Alcock 1981; Alcock and Gwynne 1987; Peakall 1990). Feeding on nectar is often observed on flowers of Myrtaceae, Xanthorrhoea (Xanthorrhoeaceae) and Hakea (Proteaceae), with comparatively few records from other plant families (Phillips et al. 2009; Brown and Phillips 2014). Use of alternative food sources has also been reported, such as the secretions of scale insects (Coccoidea) (Burrell 1935), honeydew produced by Hemiptera (Ridsdill-Smith 1970a), and extra-floral nectaries of Acacia (Fabaceae) (Bernhardt 1987). The very few species that have been studied are parasitoids of scarab beetle larvae (Janvier 1933; Burrell 1935; Given 1954; Ridsdill-Smith 1970a, b, 1971).

Currently there are no data available on how thynnine wasp communities partition resources. Further, there have been no systematic dietary studies, except for Menz et al. (2013), which focused on two species in the context of orchid pollination. A recent review spanning all genera of thynnine wasps (Brown and Phillips 2014) revealed that the most frequently visited plant family was the Myrtaceae.
However, this review relied primarily on notes from wasp specimens in museum collections, most of which do not come from systematically collected specimens. Consequently, there is likely to be a collection bias through collectors focusing on Myrtaceae, which tend to be large, floriferous trees and shrubs that attract a large abundance and diversity of insects that are easily captured (Yates et al. 2005).

In addition to understanding the mechanisms underpinning the diversity of thynnine wasp communities, dietary studies are important for resolving the habitat and ecological requirements of species involved in the pollination of rare orchids. As a by-product of mimicking the specific sex pheromone of insects, pollination by sexual deception tends to be very specific, with most orchid species relying on a single insect species for pollination (Paulus and Gack 1990; Phillips et al. 2009; Peakall et al. 2010; Gaskett 2011). As a result, some sexually deceptive orchids may be intrinsically rare through natural rarity of the pollinator (Phillips et al. 2014) or undergo declines in concert with the pollinator in modified landscapes (Pauw and Hawkins 2011). In south-western Australia, sexually deceptive orchids show a higher level of intrinsic rarity compared to species with generalist pollination strategies (Phillips et al. 2011). Further, across southern Australia numerous sexually deceptive orchid species ( $>75$ species) are listed as threatened under conservation legislation (Brown et al. 1998). As conservation of these plants relies on the maintenance of pollinator populations (Kearns et al. 1998; Menz et al. 2011), an understanding of the dietary requirements of thynnine wasps is important for the management of a large number of threatened orchid species. While understanding the requirements of pollinators is incorporated into government management plans (e.g. Department of Environment and Conservation 2008), this area of research is rarely addressed and is often not based on empirical data.

Here we undertake a community study of pollen loads carried by thynnine wasps in an area known to contain a high diversity of species, including the pollinators of threatened orchid taxa. Our objectives were to determine the role of food resources in contributing to the maintenance of highly diverse thynnine communities and to understand the habitat requirements of orchid pollinators. Specifically, we hypothesised that thynnine wasps will show resource partitioning in the type of plant species they visit for nectar.

\section{Materials and methods}

\section{Study site and species}

The study was conducted in an approximately $250 \times 500 \mathrm{~m}$ plot, located in an extensive area of natural jarrah 
(Eucalyptus marginata $\mathrm{Sm}$.) forest in the Leeuwin-Naturaliste National Park, near Yallingup, Western Australia $\left(33^{\circ} 38^{\prime} 44^{\prime \prime} \mathrm{S}, 115^{\circ} 02^{\prime} 48^{\prime \prime} \mathrm{E}\right)$. This site was chosen as thynnine wasps were known to be locally abundant based on previous observations. Furthermore, two thynnine species involved in the pollination of threatened orchid taxa (Brown et al. 1998) co-occur at the site, Zaspilothynnus nigripes Guér., the pollinator of Caladenia procera Hopper \& A.P.Br. (Phillips et al. 2009), and Macrothynnus sp. A, implicated in the pollination of Caladenia huegelli Rchb.f (Phillips et al. unpublished data).

\section{Sample collection}

Wasps were collected in spring from 13 to 23 October 2013. Sampling was done on warm $\left(>18^{\circ} \mathrm{C}\right)$, sunny days between 09:00 and 16:00 h, as wasps are less active during cold and cloudy weather (Peakall 1990). Thynnine wasps were sampled at a total of eight sites within the plot, by sweep-netting patrolling males along sandy tracks and patches of open understory. Sites were selected to maximise the chance of encountering patrolling male wasps. Sweep-netting was conducted for three 30 min periods per site on non-consecutive days, whereby it was attempted to net as many male wasps as possible. Captured wasps were placed into individual plastic vials to reduce the opportunity for pollen contamination from other individuals. Pollinators were identified morphologically by one of us (GR Brown), based on comparison with museum specimens and keys developed as part of ongoing revision of the Australian thynnine wasp fauna.

In addition to sweep-netting, pollinator baiting was conducted at the eight sites to attract thynnine species that are known to pollinate orchids. Pollinator baiting involves the presentation of picked flowers of sexually deceptive orchids to rapidly attract male thynnine wasps (Stoutamire 1983; Peakall 1990), with a new response occurring when the flowers are moved to a new position within the landscape. This is a reliable method to detect the presence of orchid pollinators (Phillips et al. 2014) and has been used extensively in experimental pollination studies. Baiting was conducted for the final $15 \mathrm{~min}$ of the sweep-netting period at each site on the first survey period. Picked flowers from five orchid species were used (pollinators given in parentheses): Caladenia procera (attracts Z. nigripes), Caladenia paludosa Hopper \& A.P.Br. (Zaspilothynnus rugicollis Turner), Caladenia thinicola Hopper \& A.P.Br. (Macrothynnus sp. A), Drakaea glyptodon Fitzg. (Zaspilothynnus trilobatus Turner) and Drakaea livida J. Drumm. (Z. nigripes) (pollinators based on data in Peakall 1990; Phillips et al. 2009, 2014). Flowers were placed on the ground in clear plastic vials filled with water, approximately $30 \mathrm{~cm}$ apart and perpendicular to any prevailing breeze.

\section{Pollen analysis}

All wasps captured were swabbed for pollen using fuchsin gel (Wooller et al. 1983). Pollen loads are strongly correlated with the extent of animal visitation to flowering plants, and are often used to determine floral resource use and foraging distances (e.g. Greenleaf et al. 2007; Beil et al. 2008; Jha et al. 2013; Menz et al. 2013). A potential limitation of this method is floral visitation without the deposition of pollen on the body of the pollinator. However, though thynnines have on rare occasion been seen taking nectar from bird-pollinated Grevillea without contacting the pollen presenter (pers. obs.), the floral morphology of members of this plant community make this unlikely.

Wasps were swabbed by repeatedly dabbing a small $\left(2 \mathrm{~mm}^{3}\right)$ cube of gel on the head, and the top and underside of the thorax. Pollen was identified under a compound microscope by comparing samples to a reference collection of pollen from all plant species flowering at the study site. The pollen load was quantified by counting all grains present in the sample collected from each wasp. Plant species represented by $<5$ pollen grains on a specimen were excluded from the dietary analysis, in case they resulted from contamination.

To investigate the relationship between wasp body size and the pollen load carried, we took morphological measurements for the ten most abundant wasp species. We measured total body length, thorax width and thorax length from five or six individuals per species. Measurements were taken using calipers to the nearest $0.1 \mathrm{~mm}$.

\section{Flowering plant community}

To determine the availability of floral resources, we counted flower heads/inflorescences for all species in flower at the time of the study, within twenty $10 \times 10 \mathrm{~m}$ quadrats. For species with inflorescences, we used the average flowers per inflorescence (using between 5 and 9 inflorescences, each from different plants) to estimate the total number of flowers. Flowers on trees overhanging the quadrat were also counted. Quadrats were arranged in two transects of 10 quadrats, through the centre of the study area.

\section{Data analysis}

Due to the similarity in plant species visited by all nectarforaging wasp species, data from all wasp species carrying pollen were pooled for analyses. The size of pollen loads of the two plant species commonly carried by the wasps were compared using a Mann-Whitney $U$ test. To test if visitation to plant species is driven by preference or differences 
in availability, the proportion of pollen loads containing pollen of each plant species was compared to the proportional abundance of flowers in the community (calculated as total abundance across the 20 flora quadrats) using a $G$ test. Mann-Whitney $U$ and $G$ tests were undertaken in GenAlEx 6.5 (Peakall and Smouse 2006, 2012).

The variables used in morphometric measurements (mean total length, thorax length and thorax width for each species) of the wasps were strongly correlated (Pearson's correlation tests, $r \geq 0.99, P \leq 0.001$ ), so only thorax width was retained for further analysis. The relationship between the mean size of pollen load carried (from all individuals per species) and mean thorax width for each wasp species was tested using linear regression. Analyses were conducted in R (R Core Team 2014).

\section{Results}

\section{Thynnine wasp community}

In total, 304 individual male thynnine wasps were collected, belonging to 28 species from 13 genera (Table S1). Of these, $18(64 \%)$ species are undescribed. The majority of species $(64 \%, N=18)$ were represented by $<10$ specimens, with nine species being represented by a single individual (Table S1). Aulacothynnus sp. A was the most abundant species, with 115 individuals being collected.

\section{Pollen analysis}

Pollen grains were recorded on 111 wasp individuals belonging to 19 species (Table 1). The wasp genera Ariphron, Eirone, Lophocheilus, Phymatothynnus, Tachynomia and Thynnid sp. C were not recorded carrying pollen loads. A total of six morphological types of pollen were recorded on thynnine wasps (only including counts with $>5$ pollen grains per pollen type per wasp individual). Two of these were readily identified as Agonis flexuosa (Willd.) Sweet (Myrtaceae) and E. marginata (Myrtaceae). Another type belonged to either Johnsonia lupulina R.Br. or Agrostocrinum stypandroides F.Muell. (Hemerocallidaceae), but could not be distinguished because of the similarity of the pollen grains of these two genera. Three pollen types (unidentified sp. A, B and C) could not be identified, and were not present in our reference collection. Pollen loads belonging to the two species of Myrtaceae were frequently detected, with pollen being recorded on 108 wasp individuals for A. flexuosa $(97.3 \%$ of individuals carrying pollen) and 37 individuals for E. marginata (33.3\% of individuals). Alternatively, pollen was identified on just one wasp each for the hemerocallid species and the unidentified sp. A, B and C (0.3\% of individuals). Both
A. flexuosa and E. marginata pollen was carried by 36 $(32.4 \%)$ wasps, whereas $66(59.5 \%)$ and $1(0.01 \%)$ wasps carried only A. flexuosa or E. marginata pollen, respectively. Of the wasp individuals carrying pollen from both species, all had larger pollen loads of A. flexuosa than E. marginata (Mann-Whitney $U$ test, $Z=3.412$, $P<0.001, N=36)($ Table 1$)$.

All wasp genera where pollen loads were recorded (Aulacothynnus, Catocheilus, Chilothynnus, Macrothynnus, Rhytidothynnus, Thynnoides, Zaspilothynnus, Zeleboria, Thynnid sp. A and Thynnid sp. B) primarily carried pollen from A. flexuosa and E. marginata. Quantification of the percentage of wasp individuals carrying pollen loads highlights pronounced interspecific variation (Table 2). Using wasp species with more than 10 sampled individuals, Macrothynnus sp. A, Macrothynnus insignis (Smith), Rhytidothynus sp. A, Zaspilothynnus nigripes and Zaspilothynnus unipunctatus Turner all had pollen loads on more than $80 \%$ of individuals, while Ariphron sp. A, Lophocheilus mammeus and Tachynomia aurifrons carried no pollen (Table 2). For the ten most abundant species, mean pollen load size was not significantly correlated with mean body size $\left(R^{2}=0.187, d f=8, P=0.118\right)$.

\section{Flowering plant community}

A total of 49 plant species from 24 families were recorded flowering at the site during the study (Table S2). Based on the total number of flowers across all plants in the quadrats, A. flexuosa was the fourth most floriferous plant in the community, making up $7.7 \%$ of the total number of flowers in the community (Table S2). Alternatively, $E$. marginata was only the fourteenth most floriferous member of the flowering community, making up $0.2 \%$ of the total number of flowers in the community. While Pimelea rosea R.Br. (Thymelaceae; 33,000 flowers), Pimelea spectabilis Lindl. (Thymelaceae; 15,600 flowers) and $S y$ naphea floribunda A.S.George (Proteaceae; 10,500) were the most floriferous plants in the community (Table S2), none of the thynnine individuals carried pollen from these species. Plant species were not used in proportion to their availability $(G=31489, d f=48, P<0.001$; Fig. 1$)$.

\section{Discussion}

We recorded a total of 28 species of thynnine wasps cooccurring at the study site. Importantly, the high number of undescribed taxa $(N=18,64 \%)$ recorded in this study highlights the need for increased museum collections and ongoing research into the taxonomy of this diverse family of parasitoid wasps. Surprisingly, despite the high diversity of plant species flowering at the site (49 species), analysis 


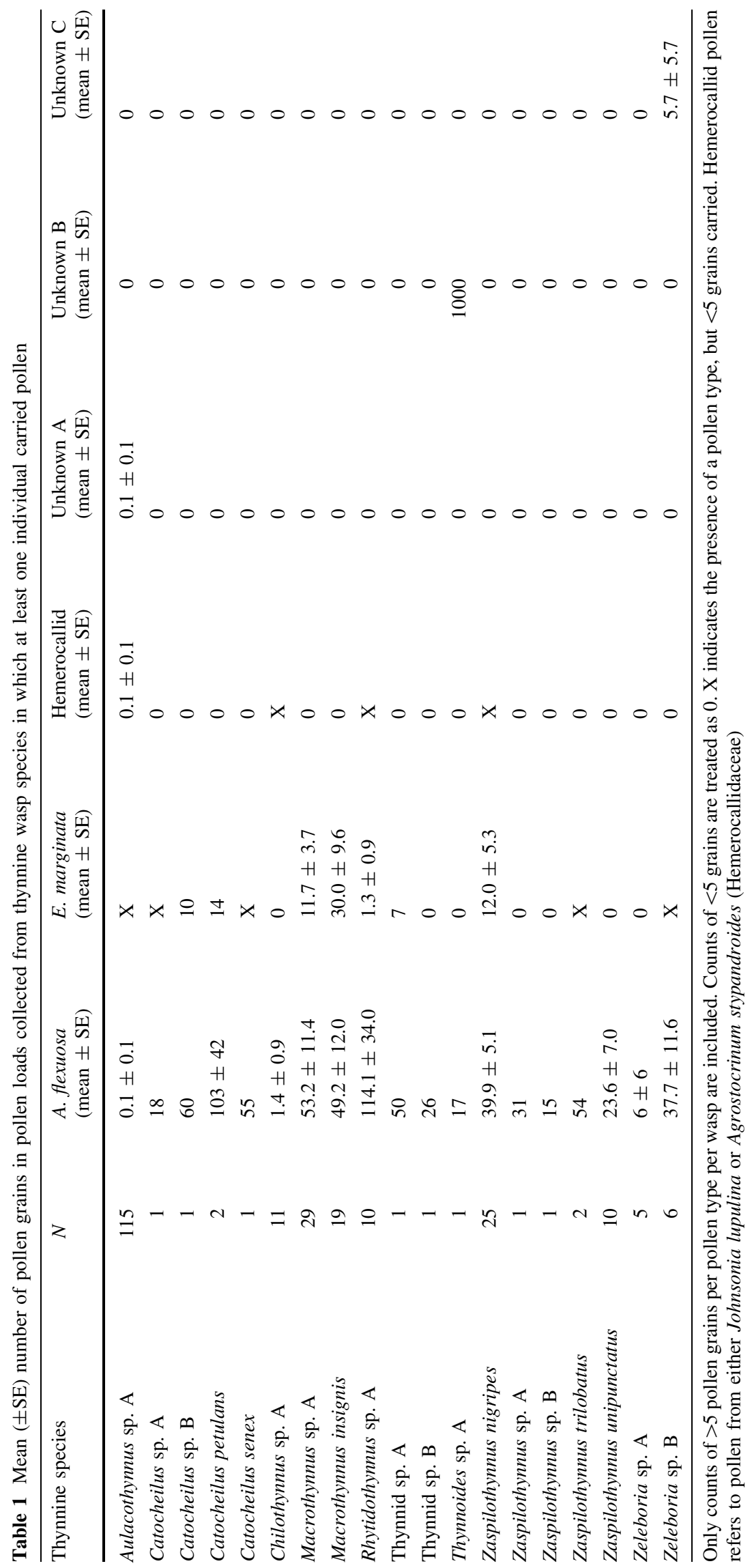




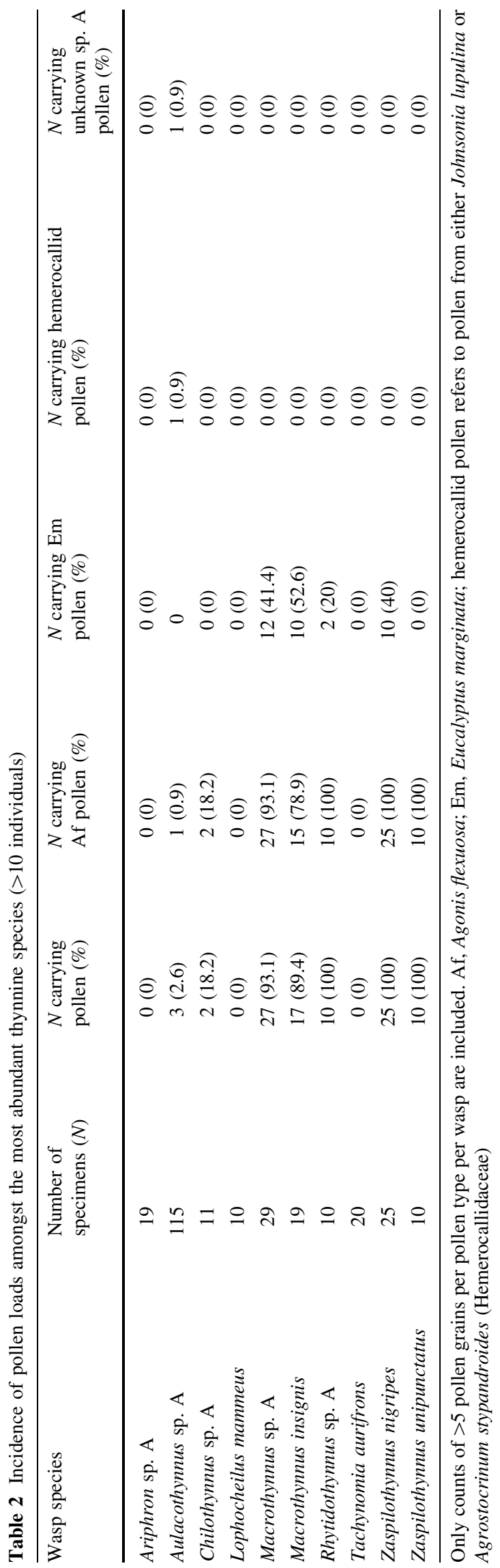

of pollen loads revealed that the wasps were utilising only a very small proportion of the flowering community. The majority of individuals carrying pollen were exclusively visiting two species, A. flexuosa and E. marginata, which supports field observations of thynnines feeding on these plant species (pers. obs.). The four other pollen types represented were each only detected on one individual. Given the diversity of wasp species $(N=15,54 \%$ of the community) feeding on both A. flexuosa and E. marginata, we consider that there is no evidence of nectar resource partitioning within this community of nectar-feeding thynnines.

Our results show that nectar-feeding thynnines tend to be specialised on generalist plant species. This specialization by pollinators on generalist plant species is a consistent structural characteristic of plant-pollinator networks (Vázquez and Aizen 2004; Bascompte et al. 2006; Bascompte and Jordano 2007). At our study site, the two frequently visited plant species were both open-flowered Myrtaceae, supporting findings from previous studies that have predicted the importance of Myrtaceae as a carbohydrate source for thynnines (Menz et al. 2013; Brown and Phillips 2014). These plants are also important nectar resources for many other insect and vertebrate species. For example, Yates et al. (2005) demonstrated that E. marginata was visited by over 80 species of insect from 38 families in an urban bushland remnant. The question arises as to what is the carbohydrate source utilized by those species in the community that weren't found to be carrying pollen? It is likely that these species are exploiting alternative carbohydrate sources, such as the exudates of phloem-feeding Homoptera or scale insects (see Brown and Phillips 2014). A possible method for elucidating foraging on alternative carbohydrate sources would be the use of stable isotopes (Layman et al. 2012).

The specialization on nectar plants seen in this system may in part be due to morphological limitations of the wasps. While some thynnines have relatively elongated mouthparts compared to other species, the species collected in the present study have short mouthparts that limit access to deeper or tubular flowers (Brown and Phillips 2014). While the flowers of these Myrtaceae are open-faced, allowing easy access to nectar, some species with abundant flowers, such as Pimelea rosea and P. spectabilis have very long corolla tubes, potentially excluding access to nectar by thynnines. Similarly, despite being abundant, Synaphea floribunda was not visited by thynnines, possibly due to the small, tubular nature of the flowers. Several species at the site, such as members of Hibbertia and Acacia (Table S2) do not produce nectar and primarily attract pollen-foraging insects, such as beetles and bees (Keighery 1975; Bernhardt 1987). Thus, there are few species in the community that may be available to thynnines as a nectar source, 


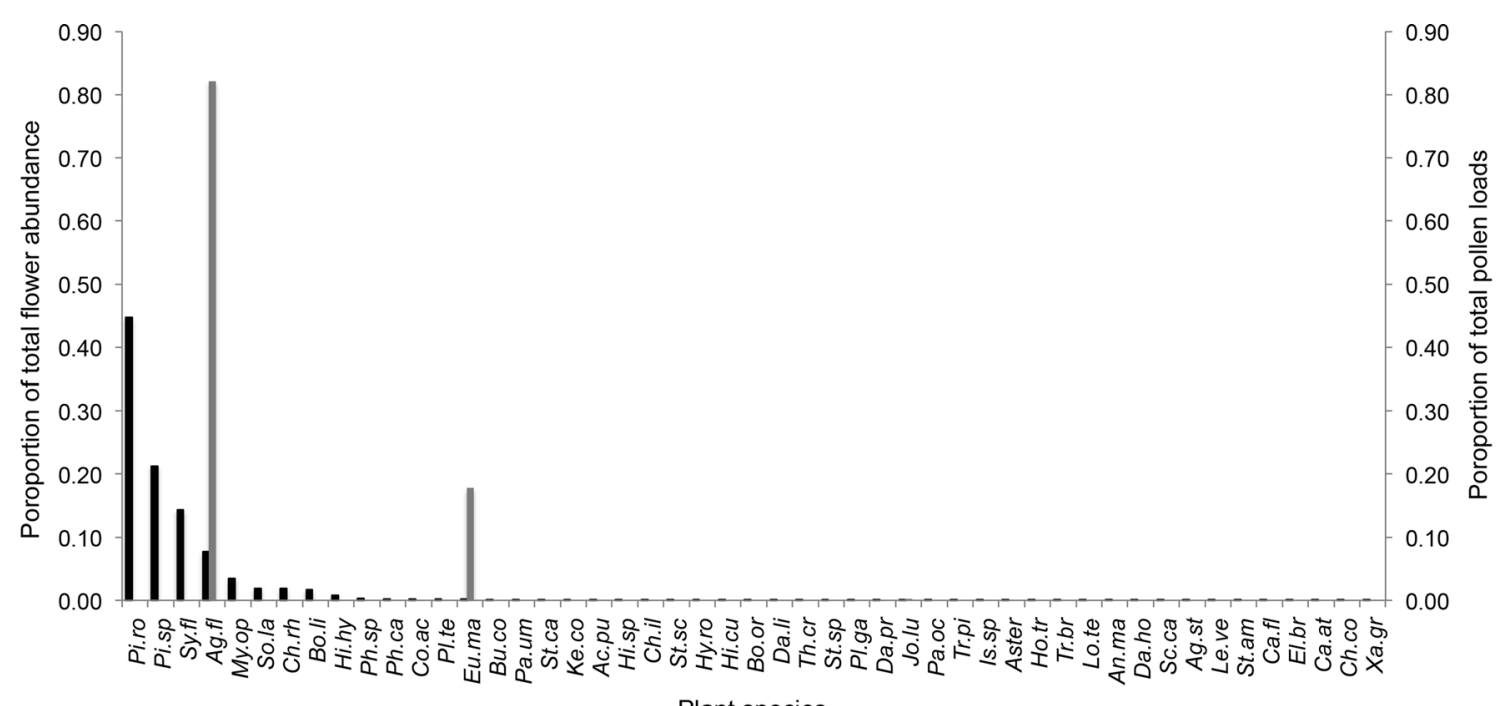

Plant species

Fig. 1 Proportion of total flower abundance (black bars) and pollen load (gray bars) for each plant species, calculated from the floral counts in the quadrats $(N=20)$, and all pollen loads from all wasp species combined $(N$ individuals $=108)$. Data for the three unidentified pollen types is not included. Plant species are sorted in order of abundance. Full plant species names (alphabetical order): Ac.pu, Acacia pulchella; Ag.fl, Agonis flexuosa; Ag.st, Agrostocrinum stypandroides, An.ma, Anigozanthos manglesii; Aster, Asteraceae sp.; Bo.li, Bossiaea linophylla; Bo.or, Bossiaea ornata; Bu.co, Burchardia congesta; Ca.at, Caladenia attingens; Ca.fl, Caladenia flava; Ch.co, Chamaescilla corymbosa; Ch.il, Chorizema ilicifolium; Ch.rh, Chorizema rhombeum; Co.ac, Conostylis aculeata; Da.ho, Dasypogon hookeri; Da.li, Dampiera linearis; Da.pr, Daviesia preissii; El.br, Elythranthera brunonis; Eu.ma, Eucalyptus marginata;

potentially resulting in many species utilising the readily accessible flowers of these Myrtaceae. Additionally, E. marginata could be favored as it produces nectar with a relatively high sugar concentration $(55.3 \%$, Yates et al. 2005).

Specialization on these species of Myrtaceae could be facilitated if nectar is not limiting the population size of thynnine wasps in this community. In this scenario, there would be no selection for pollinators to diversify their foraging niche to consume nectar from plants that produce less nectar reward or have more inaccessible flowers. To evaluate this possibility would require data on nectar production and sugar concentration, coupled with estimates of field metabolic rates of thynnine wasps. While technically challenging, the recent development of using radioactive rubidium $(86 \mathrm{Rb})$ to measure metabolic rates in insects (Tomlinson et al. 2014) suggests that this may be a powerful approach for understanding resource constraints and competition in thynnine wasps.

Interspecific variation in host use may be an important mechanism to facilitate the co-occurrence of numerous species of parasitoids (e.g. Smith et al. 2008; Bailey et al. 2009). There is very little known about host use of thynnine
Hi.cu, Hibbertia cunninghamii; Hi.hy, Hibbertia hypericoides; Hi.sp, Hibbertia sp.; Ho.tr, Hovea trisperma; Hy.ro, Hypocalymma robustum; Is.sp, Isopogon sp.; Jo.lu, Johnsonia lupulina, Ke.co, Kennedia coccinea; Le.ve, Leucopogon verticillatus; Lo.te, Lobelia tenuior; My.op, Myoporum oppositifolium; Pa.oc, Patersonia occidentalis; Pa.um, Patersonia umbrosa var. xanthina; Ph.ca, Phyllanthus calycinus; Ph.sp, Philotheca spicatum; Pi.ro, Pimelea rosea; Pi.sp, Pimelea spectabilis; Pl.ga, Platytheca galioides; Pl.te, Platysace tenuissima; Sc.ca, Scaevola calliptera; So.la, Sowerbaea laxiflora; St.am, Stylidium amoenum; St.ca, Stylidium calcaratum; St.sc, Stylidium schoenoides; St.sp, Styphelia sp.; Sy.fl, Synaphea floribunda; Th.cr, Thelymitra crinita; Tr.br, Tripterococcus brunonis; Tr.pi, Trachymene pilosa; Xa.gr, Xanthorrhoea gracilis

wasps, but the few studies conducted have shown that hosts tend to be Scarabeid beetle larvae (Janvier 1933; Burrell 1935; Given 1954; Ridsdill-Smith 1970a, b, 1971). One laboratory study investigating host use in the thynnine wasp Hemithynnus hyalinatus demonstrated that females successfully parasitised up to six species of Scarabeid larvae (Ridsdill-Smith 1970a). However, thynnines may be more generalised in their host use under laboratory conditions than in the field. We predict that diverse thynnine communities may form through host partitioning, potentially through species-specific interactions, utilization of different developmental stages of the same host species, or spatial partitioning within the soil profile (see RidsdillSmith 1970b). Furthermore, multiple thynnine species may rely on a few highly abundant host species. Host use is a significant gap in our understanding of thynnine biology and is in urgent need of further research.

\section{Implications for the conservation of rare orchid pollinators}

We recorded the presence of two species of thynnine, Macrothynnus sp. A and Z. nigripes, which are involved in 
the pollination of rare orchids. Analysis of the pollen loads carried by $M$. sp. A and $Z$. nigripes, indicated that these species exclusively carried pollen from open-flowered Myrtaceae, namely A. flexuosa and E. marginata. Both of the rare orchid species that exploit these wasps are believed to be reliant solely on sexually deceived pollinators to achieve pollination (Phillips et al. 2009; Phillips et al. unpublished data). While we have demonstrated the importance of A. flexuosa and E. marginata as food resources for these insects, observations of feeding thynnines from other sites suggest that several other Myrtaceae will be used when available. These Myrtaceae tend to be larger shrubs and trees, which may be a limitation in some regions of south-western Australia, particularly the Swan Coastal Plain, which is heavily cleared and the remaining vegetation highly fragmented (How and Dell 2000; Davis et al. 2013). Given our lack of knowledge regarding host use of these wasps, a precautionary approach would be to protect the remaining habitat as a whole to ensure populations are maintained. Furthermore, the restoration of floriferous Myrtaceae in proximity to habitat remnants may assist in supporting thynnine populations during crucial reproductive periods.

Acknowledgments Funding was provided by Jandakot Airport Holdings and an Australian Research Council linkage grant (LP110100408) to KWD and Rod Peakall. The fieldwork was also supported by a grant from the Holsworth Wildlife Research Endowment awarded to MHMM. Special thanks to Ms. E. David for field and laboratory assistance.

\section{References}

Alcock J (1981) Notes on the reproductive behavior of some Australian thynnine wasps (Hymenoptera: Tiphiidae). J Kansas Entomol Soc 54:681-693

Alcock J, Gwynne DT (1987) Courtship feeding and mate choice in thynnine wasps (Hymenoptera: Tiphiidae). Aust J Zool 35:451458

Austin AD, Yeates DK, Cassis G, Fletcher MJ, La Salle J, Lawrence JF, McQuillan PB, Mound LA, Bickel DJ, Gullan PJ, Hales DF, Taylor GS (2004) Insects 'Down Under'-diversity, endemism and evolution of the Australian insect fauna: examples from select orders. Aust J Entomol 43:216-234

Bailey R, Schönrogge K, Cook JM, Melika G, Csóka G, Thuróczy C, Stone GN (2009) Host niches and defensive extended phenotypes structure parasitoid wasp communities. PLoS Biol 7:e1000179. doi:10.1371/journal.pbio.1000179

Bascompte J, Jordano P (2007) Plant-animal mutualistic networks: the architecture of biodiversity. Annu Rev Ecol Evol Syst 38:567-593

Bascompte J, Jordano P, Olesen JM (2006) Asymmetric coevolutionary networks facilitate biodiversity maintenance. Science 312:431-433

Beil M, Horn H, Schwabe A (2008) Analysis of pollen loads in a wild bee community (Hymenoptera: Apidae) — a method for elucidating habitat use and foraging distances. Apidologie 39:456-467
Bernhardt P (1987) A comparison of the diversity, density, and foraging behavior of bees and wasps on Australian Acacia. Ann Mo Bot Gard 74:42-50

Bohman B, Phillips RD, Menz MHM, Berntsson BW, Flematti GR, Barrow RA, Dixon KW, Peakall R (2014) Discovery of pyrazines as pollinator sex pheromones and orchid semiochemicals: implications for the evolution of sexual deception. New Phytol 203:939-952

Bower CC (1996) Demonstration of pollinator-mediated reproductive isolation in sexually deceptive species if Chiloglottis (Orchidaceae: Caladeniinae). Aust J Bot 44:15-33

Brown GR (2009) Description of two pseudaposematic species with a review of defensive adaptations in the subfamily Thynninae (Hymenoptera: Thynnidae). Beagle (Darwin) 25:71-78

Brown GR, Phillips RD (2014) A review of the diet of flower wasps (Hymenoptera: Thynnidae: Thynninae). North Territ Nat 25:50-63

Brown AP, Thomson-Dans C, Marchant N (1998) Western Australia's threatened flora. Department of Conservation and Land Management, Perth

Burrell RW (1935) Notes on the habits of certain Australian Thynnidae. J N Y Entomol Soc 43:19-29

Davis RA, Gole C, Roberts JD (2013) Impacts of urbanisation on the native avifauna of Perth, Western Australia. Urban Ecosyst $16: 427-452$

Department of Environment and Conservation (2008) Grand Spider Orchid (Caladenia huegelii) Interim Recovery Plan 2008-2013. Interim Recovery Plan No. 272. Department of Environment and Conservation, Western Australia

Gaskett AC (2011) Orchid pollination by sexual deception: pollinator perspectives. Biol Rev 86:33-75

Given BB (1954) Evolutionary trends in the Thynninae (Hymenoptera: Tiphiidae) with special reference to feeding habits of Australian species. Trans R Entomol Soc London 105:1-10

Greenleaf SS, Williams NM, Winfree R, Kremen C (2007) Bee foraging ranges and their relationship to body size. Oecologia 153:589-596

Griffiths KE, Trueman JWH, Brown GR, Peakall R (2011) Molecular genetic analysis and ecological evidence reveals multiple cryptic species among thynnine wasp pollinators of sexually deceptive orchids. Mol Phylogenet Evol 59:195-205

Hopper SD, Brown AP (2007) A revision of Australia's hammer orchids (Drakaea: Orchidaceae), with some field data on species-specific sexually deceived wasp pollinators. Aust Syst Bot 20:252-285

How RA, Dell J (2000) Ground vertebrate fauna of Perth's vegetation remnants: the impacts of 170 years of urbanization. Pac Conserv Biol 6:198-217

Janvier H (1933) Études biologiques de quelques Hymenoptères du Chili. Ann Sci Nat Zool 16:209-356

Jervis MA, Kidd NAC, Fitton MG, Huddleston T, Dawah HA (1993) Flower-visiting by hymenopteran parasitoids. J Nat Hist 27:67-105

Jervis MA, Ellers J, Harvey JA (2008) Resource acquisition, allocation, and utilization in parasitoid reproductive strategies. Annu Rev Entomol 53:361-385

Jha S, Stefanovich L, Kremen C (2013) Bumble bee pollen use and preference across spatial scales in human-altered landscapes. Ecol Entomol 38:570-579

Kearns CA, Inouye DW, Waser NM (1998) Endangered mutualisms: the conservation of plant-pollinator interactions. Annu Rev Ecol Syst 29:83-112

Keighery GJ (1975) Pollination of Hibbertia hypericoides (Dilleniaceae) and its evolutionary significance. J Nat Hist 9:681-684

LaSalle J, Gauld ID (1991) Parasitic Hymenoptera and the biodiversity crisis. Redia 74:315-334 
Layman CA, Araujo MS, Boucek R, Hammerschlag-Peyer CM, Harrison E, Jud ZR, Matich P, Rosenblatt AE, Vaudo JJ, Yeager LA, Post DM, Bearhop S (2012) Applying stable isotopes to examine food-web structure: an overview of analytical tools. Biol Rev 87:545-562

Levine JM, HilleRisLambers J (2009) The importance of niches for the maintenance of species diversity. Nature 461:254-257

MacArthur RH (1958) Population ecology of some warblers of northeastern coniferous forests. Ecology 39:599-619

MacArthur RH, MacArthur JW (1961) On bird species diversity. Ecology 42:594-598

Menz MHM, Phillips RD, Winfree R, Kremen C, Aizen MA, Johnson SD, Dixon KW (2011) Reconnecting plants and pollinators: challenges in the restoration of pollination mutualisms. Trends Plant Sci 16:4-12

Menz MHM, Phillips RD, Dixon KW, Peakall R, Didham RK (2013) Mate-searching behaviour of common and rare wasps and the implications for pollen movement of the sexually deceptive wasps they pollinate. PLoS One 8:e59111. doi:10.1371/journal. pone.0059111

Menz MHM, Phillips RD, Anthony JM, Bohman B, Dixon KW, Peakall R (2015) Ecological and genetic evidence for cryptic ecotypes in a rare sexually deceptive orchid, Drakaea elastica. Bot J Linn Soc 177:124-140

Paulus HF, Gack C (1990) Pollinators as prepollinating isolation factors: evolution and speciation in Ophrys (Orchidaceae). Israel J Bot 39:43-79

Pauw A, Hawkins JA (2011) Reconstruction of historical pollination rates reveals linked declines of pollinators and plants. Oikos 120:344-349

Peakall R (1990) Responses of male Zaspilothynnus trilobatus Turner wasps to females and the sexually deceptive orchid it pollinates. Funct Ecol 4:159-167

Peakall R, Smouse PE (2006) GENALEX 6: genetic analysis in Excel Population genetic software for teaching and research. Mol Ecol Notes 6:288-295

Peakall R, Smouse PE (2012) GenAlEx 6.5: genetic analysis in Excel. Population genetic software for teaching and research-an update. Bioinformatics 28:2537-2539

Peakall R, Ebert D, Poldy J, Barrow RA, Francke W, Bower CC, Schiestl FP (2010) Pollinator specificity, floral odour chemistry and the phylogeny of Australian sexually deceptive Chiloglottis orchids: implications for pollinator-driven speciation. New Phytol 188:437-450

Phillips RD, Faast R, Bower CC, Brown GR, Peakall R (2009) Implications of pollination by food and sexual deception for pollinator specificity, fruit set, population genetics and conservation of Caladenia (Orchidaceae). Aust J Bot 57:287-306

Phillips RD, Brown AP, Hopper SD, Dixon KW (2011) Orchid biogeography and factors associated with rarity in a biodiversity hotspot, the Southwest Australian Floristic Region. J Biogeogr 38:487-501

Phillips RD, Peakall R, Hutchinson MF, Linde CC, Xu T, Dixon KW, Hopper SD (2014) Specialized ecological interactions and plant species rarity: the role of pollinators and mycorrhizal fungi across multiple spatial scales. Biol Conserv 169:285-295

Pianka ER (1973) The structure of lizard communities. Annu Rev Ecol Syst 4:53-74

R Core Team (2014) R: a language and environment for statistical computing. R Foundation for Statistical Computing, Vienna, Austria. http://www.R-project.org/

Ridsdill-Smith TJ (1970a) The behaviour of Hemithynnus hyalinatus (Hymenoptera: Tiphiidae), with notes on some other Thynninae. J Aust Entomol Soc 9:196-208

Ridsdill-Smith TJ (1970b) The biology of Hemithynnus hyalinatus (Hymenoptera: Tiphiidae), a parasite on scarabeid larvae. J Aust Entomol Soc 9:183-195

Ridsdill-Smith TJ (1971) Field notes on the occurrence of Hemithynnus hyalinatus (Hymenoptera: Tiphiidae) as a parasite of scarabeids on the New England Tablelands. J Aust Entomol Soc 10:265-270

Schiestl FP, Peakall R, Mant JG, Ibarra F, Schulz C, Francke S, Francke W (2003) The chemistry of sexual deception in an orchid-wasp pollination system. Science 302:437-438

Smith AM, Rodriguez JJ, Whitfield JB, Deans AR, Janzen DH, Hallwachs W, Hebert PDN (2008) Extreme diversity of tropical parasitoid wasps exposed by iterative integration of natural history, DNA barcoding, morphology, and collections. Proc Natl Acad Sci USA 105:12359-12364

Stoutamire WP (1974) Australian terrestrial orchids, thynnid wasps, and pseudocopulation. Am Orchid Soc Bull 43:13-18

Stoutamire WP (1983) Wasp-pollinated Species of Caladenia (Orchidaceae) in South-western Australia. Aust J Bot 31:383394

Tomlinson S, Mathialagan PD, Maloney SK (2014) Special K: testing the potassium link between radioactive rubidium $(86 \mathrm{Rb})$ turnover and metabolic rate. J Exp Biol 217:1040-1045

Vázquez DP, Aizen MA (2004) Asymmetric specialization: a pervasive feature of plant-pollinator interactions. Ecology 85: $1251-1257$

Veijalainen A, Wahlberg N, Broad GR, Erwin TL, Longino JT, Sääksjärvi IE (2012) Unprecedented ichneumonid parasitoid wasp diversity in tropical forests. Proc R Soc B 279:46944698

Veijalainen A, Sääksjärvi IE, Tuomisto H, Broad GR, Bordera S, Jussila R (2014) Altitudinal trends in species richness and diversity of Mesoamerican parasitoid wasps (Hymenoptera: Ichneumonidae). Insect Conserv Divers 7:496-507

Wäckers FL (2004) Assessing the suitability of flowering herbs as parasitoid food sources: flower attractiveness and nectar accessibility. Biol Control 29:307-314

Wooller RD, Russell EM, Renfree MB (1983) A technique for sampling pollen carried by vertebrates. Aust Wildlife Res 10:433-434

Yates CJ, Hopper SD, Taplin RH (2005) Native insect flower visitor diversity and feral honeybees on jarrah (Eucalyptus marginata) in Kings Park, an urban bushland remnant. J R Soc West Aust $88: 147-153$ 